\title{
Integrating Augmented Reality in the Social Media Platforms. The Users' Perspective
}

\author{
Alina Simona Tecau \\ alina tecau@unitbv.ro \\ Bianca Tescasiu \\ bianca.tescasiu@,unitbv.ro \\ Cristinel Petrisor Constantin ${ }^{\star}$ \\ cristinel.constantin@unitbv.ro \\ Transilvania University of Brasov, Romania
}

\begin{abstract}
This paper presents the results of a qualitative research based on the paper and pencil method with the aim to identify the social network users' opinions about the opportunities to develop a revolutionary technology which integrates Augmented Reality (AR) with social networks in order to create a meeting platform that might be used by stakeholders, such as social media users, producers and consumers in order to experience new opportunities of gaining relevant information. The research was conducted among 52 potential users and the results reveal that AR can potentiate the using of social networks; from the marketing point of view both consumers and products suppliers can record significant benefits on their market experience. Thus, AR Media platform development can also have positive implications for the education system.
\end{abstract}

Keywords: augmented reality (AR), social network, consumer needs, AR Media, marketing strategies, information technology (IT)

JEL Code: M21, M31, O32, O35

\section{Introduction}

The efforts to develop new information technologies and products based on Virtual Reality (VR) and Augmented Reality (AR) have increased in lately and the specialty literature largely debate the advantages of such technologies, especially for the marketing activity $[8,10$, 14]. The preoccupation for including AR in social networks has also become fashionable $[5,11]$ and, in this sense, the researches have to focus on the best solutions for this process of integration. In this context the development of a social network, called AR Media, has been proposed. This network will use AR in order to improve the interaction and the interactivity between users. Thus, "the users of the AR Media online network will only need a camera mobile device to scan the image of a building, location, or person, thus ensuring instant access to its associated profile within the AR Media social network or information about the user activity on its LinkedIn, Twitter, Flickr, Youtube, Spotify, or other networks accounts"[16].

The main research question, which arises regarding the above mentioned network, is: "in what manner will accept the users this new product?" Starting from this question, the following research objectives were established: (O1) to find the opinions of young people regarding the relationship between using $A R$ and the development of social networks; (O2) to identify the opinions about positive and negative effects of using AR Media; (O3) to find the people needs regarding the using of $A R$ in social networks; (O4) to generate ideas regarding the future development of AR Media.

The results revealed that using AR in social networks would create new experiences for users, which could become better informed about a certain product. For these features such a 
network can record an impressive success among users. In the sample members' opinions, by using AR Media both individuals and companies might receive benefits due to a better communication.

The remainder part of this article contains a short literature review regarding the importance of AR for the future marketing actions and the integration of AR on social networks (Section 2), followed by a description of the research methodology (Section 3), research results and discussion (Section 4) and conclusions (Section 5).

\section{Literature review}

AR represents an integration of virtual information in a real world, able to change the users' perception by using this additional information [8]. AR uses different interfaces like phone, tablets, smart watches, computers, that could bring virtual things in the present reality in order to enrich the users' perceptions about aspects that cannot be directly touched [9, 12]. By this characteristic of overlapping information to a real context, AR differs from Virtual Reality (VR), which immerses people in other contexts that are not in their proximity [2]. As the technologies that enable using of AR have been strongly developed during the last years, the research interest in this field increased very fast [3]. Nevertheless, the real impact of AR is considered to be not enough studied in literature in spite of its potential for future marketing relations [8].

Some studies published in literature highlight the power of AR as a marketing tool that is able to generate sales because the consumers can have a unique experience with product features [10]. Thus, the AR could be used successfully in advertising, including on-line advertising, but ethical and legal issues should be considered [14]. Other studies reveal the opportunity to use AR in corporate management, where AR applications (e.g. games that put in evidence specific skills) could be used to recruit the best employees [15].

AR could be also used in specific domains that are suitable for this technology, like real estate [13] or agriculture [7]. In such cases AR could be used to bring more information in a real context in order to enrich the decision process. The aspects related to improving the image of heritage monuments or tourism objectives by using AR are also debated in literature with the aim to highlight the benefits offered by this new technology. Thus, the AR could offer to people an image of building outdoors that are in reconstruction and that are not directly accessible to people. In this respect, a set of pictures from different periods of time could be mixed in order to create an image that is much closed to the real one [6]. Such a technology may also serve to make available for the tourist the image of a certain heritage object (like a building), which does not exist anymore in present [1]. In fact, the tourism industry is considered one of the most important beneficiaries of new technologies, including AR [4].

Due to its advantages and large applicability AR could be used in social networks to help users in obtaining new experiences, but this connection is not largely debated in literature. One of such studies proposes to use AR and face-signature to connect people that are "physically nearby" with the aim to share information of interest [11]. Other studies highlight the opportunity to use current social networks, like Facebook, to share personal information using $A R$ and images of persons or objects [5]. Starting from these considerations our study aimed to find the user's perspectives about the ways that AR could be integrated in social media platforms.

\section{Methods}

In order to achieve the research objectives a "paper and pencil" interview has been used. This is a structured interview, which involves a face-to-face discussion based on a structured questionnaire containing open questions. The interviewer tried to capture as many issues as possible, and, depending on the answers received from the subjects, other more specific questions have been asked in order to reach deeper levels of the research problem. Other important aspects that are important for the information relevance were considered: the way of approaching the participants, the appropriate introduction of the research problem, the accuracy of the questions addressed, the way in which the interview ends. 
Every interview began with a brief presentation of AR Media and other relevant notions so that the researcher can ensure that every participant has at least a minimum of knowledge in the field, which allows them to answer easily to the questions. A number of eight open questions were asked and finally 52 interviews were conducted. The questions targeted the research objectives in such a manner to have a clear meaning for every respondent and to assure consistent answers.

Collected data were processed by using Content Analysis - a method specific to exploratory research. The answers received from interviewees were analyzed according to their content and were coded so that the answers with the same signification would receive the same code. An analysis grid has been performed and two types of synthesis have been made on the table's rows and columns: horizontal analysis and vertical analysis. The interpretation of each analysis was realizes by three researchers. Those situations when they had different opinions about certain issues were discussed until a consensus was reached.

\section{Results and discussions}

The summary of the information obtained as well as the overall conclusions of the research are presented below, these being grouped on specific results obtained for each objective of the research.

(O1) to find the opinions of young people regarding the relationship between using $A R$ and the development of social networks;

Out of the 52 interviewees 45 consider that using AR in social networks will have a positive impact on the development of Social Media. They have associated the idea of launching AR Media platform with expressions such as: "high/significant impact, instant interaction, raising the barriers between the real and the digital world, better communication, authentic experience, a boom, a step forward in the field of technology and of augmented reality".

Most interviewees believe that young people will be the most receptive to the idea of joining this platform after its launch. The descriptions made by the sample members are encouraging for the potential developers of this possible social network. Among these descriptions the most relevant are the following:

"An online socialization platform, such as AR Media, which uses angmented reality, will raise that barrier between the real world and the digital world, the interaction between users being able to take place instantly. From the point of view of organizations, they will be able to communicate much better with the target audience, even offering them some personalized services and support."(\# 4).

"Using AR on social networks will have a high impact, because it offers a much more authentic experience of using a certain product. The launch of such a social network will be a boom among Internet users." (\# 6)

"The impact will be significant, especially among young people and those that are application and social networks lovers" (\# 15),

"Such a platform will be well received and appreciated, used by many people, especially on the backeground of technological advancement and the high degree of consumer acceptance of new technologies." (\# 25)

"The impact of launching and development of the AR Media will be a positive one, with a continuous development, as the population will easily adapt to a new concept such as this one. These new functions will be appreciated by consumers and they will be determined to use and develop this platform further. "(\# 27)

Taking into consideration the above statements of potential users of AR Media reveal a positive relationship between using AR and the future development of Social Media. Especially 
young people are considered the main users of such a platform opened to live new experiences and to contribute to the development of AR media by uploading new content and applications.

(O2) to identify the opinions about positive and negative effects of using AR Media;

The respondents have identified several advantages of this social network, such as: "the originality of idea", "new experiences it can generate", "memorable sensations", "pleasant experiences", "curiosity" and so on. Such positive effects are stressed in the interviewees' discourses:

"The application would have a plus due to the originality of the idea itself. Consumers will be curious to try and use the AR Media app at least once. Also, the organization has the opportunity to promote itself in an innovative, unique way. "(\# 28)

"With the implementation of this technology the ways in which people live, work and consume information will fundamentally change. Their curiosity must be aroused by offering memorable sensations. "(\# 35)

"The impact will be a positive one as the application can be used on the mobile phone, being always available to the user. The interactivity will generate pleasant experiences that will be able to be shared with friends and thus generating the effect of viralization." (\# 15)

"The launch of this social network in the online environment will create a revolution, as it will penetrate a market dominated by Facebook. Given that it will be a more interactive environment, many users will try the interaction with augmented reality. (\# 39)

"Shopping will become much simpler in the online environment, as buyers will be able to test certain products directly on their personal devices (clothes, shoes, furniture dimensions)" (\# 21)

One of the advantages of this potential platform, highlighted by several participants, is the ease of gathering information that an entity posts on all social networks, thus giving the possibility to create an overview of the online activity of that entity. Thus, people can generally have pleasant experiences due to the current context of technological development of social networks.

In spite of the above mentioned positive effects of using AR in social networks, some negative impacts have been stressed by the interviewed persons. In their opinions the main negative impact will be on the information confidentiality. Thus, some conflicts between the users and the network's owners could appear. Possible conflicts and competitive actions could also arise between the existing social networks.

(O3) to find the people needs regarding the using of $A \mathrm{R}$ in social networks;

The research participants identified the need of information as the main need which can be satisfied by using AR Media because a lot of details can be obtained in real time and in an easy way of accessing data. According to the most of participants' opinions, users will be aware that the combination of the physical reality with the virtual one could change people's lives. "The way we live, work and the way we consume information will gain other meanings," said one of the participants. (\# 7)

Other needs mentioned by the interviewed subjects were: the need to increase the emotional connectivity between the network users, the need for communication, the need to express their thoughts, the need to interact with other people, the need for development, knowledge, education, the need of entertainment, memorable sensations, unique and authentic experiences. Referring to the need of group belonging, one of the participants stated: "people will want to integrate into certain groups, and through this network they will be able to discover those people with the same characteristics and whishes." (\# 35) 
One of the most important needs considered by respondents is related to a new trend outlined in the last period of time, which is focused by eliminating the barriers between the real and virtual world. People are increasingly interested to find detailed information about a certain issue or products offered on market. In order to satisfy this need, AR might break some barriers in the informing process by bringing significant virtual features in the real world. These results are in line with other findings presented in literature, which underline the role of AR in enriching consumers' experiences $[9,12]$.

(O4) to generate ideas regarding the future development of AR Media;

According to the most of interviewees, in order to make AR Media more attractive than the other existing social networks, additional functions should be added to the main function offered at the by the usual networks communication through messages, the possibility to keep pictures, thoughts, articles, possibility to follow or exclude certain pages). The main ideas mentioned by respondents regarding the additional functions that AR Media should offer were: possibility to browse without being disturbed by advertisements, optimal functionality, requesting permission to update when appropriate, and low storage space in the phone memory. In this respect, an application able to work both with Android and iOS systems should be developed. Such an application can use voice control in order to take photos in virtual space but also to use augmented reality to create conversations between users like they are in the same space, even if they are not nearby.

The research participants believe that the marketing strategies and policies of the companies will be mostly influenced by using AR. The companies will need to use AR especially to outline a better image. Through AR Media they can impress their customers by: appearance, effects, memorable images about products / services; they can make the consumers to understand better the benefits they offer or even have access to the product. Such features cannot be offered through a classic website or brochure. In this respect two of participants' statements are expressive:

\footnotetext{
"Promotion would become an" art "in which original ideas are transposed, stage which is hardly achievable in the offline environment." (\# 13) ".
}

"Companies can put an information billboard with certain messages at the entrance of the buildings, such us: Scan us and AR Media will tell you our story! or Give us a picture with AR Media and you will find out what we do! " (\# 15)

These results also are in line with other findings from literature that consider AR a powerful marketing tool able to generate new experiences and to enhance the impact of promotion actions $[10,14]$. Therefore companies will be the most important engine in the future development of AR Media.

\section{Conclusions}

According to the obtained results, the attractiveness of the AR Media social network is high among the interviewed participants. They debated with increasing interest the researched topic with many ideas meant to develop the functionality of AR Media network. The main strong points identified by respondents are the high level of interactivity and the use of AR, one of the state-of-the-art technologies, which can be considered an innovative product able to attract a large number of users. These strong points are facilitated by some opportunities related to the users opening to use social networks and increasing popularity of AR. The development of AR Media network will offer a lot of benefits mainly to the consumers of different products that could be promoted through such a platform. The companies are also one of the main beneficiary but they have to make major investments both in people and technology in order to be able to 
use this platform. Nevertheless the success in using AR Media will determine a strong competitive advantage with a strong profit on medium and long term.

The main limits of this research are given by the impossibility to extend the obtained results to a general accepted level. These limits are due mainly to the specificity of researches based on qualitative data and unrepresentative sample, which includes only 52 interviewees from only one city of Romania (Brașov city). Starting from these aspects, further researches should extend the investigations to the national level. Another research direction is the testing of a demonstrative model of AR Media in order to find users' opinions after an effective contact with such a social network.

The main implications of our results are relevant for the business environment, especially for the developers of AR Media network, but also for those companies that are opened to using this new technology. They can use the ideas provided by potential users to develop future strategies of their marketing policy. All these needs and future actions performed by companies can contribute further to the development of marketing theory, with strong implications on educational system.

\section{Acknowledgements}

The authors would like to acknowledge that this paper is financed by the Executive Agency for Higher Education, Research, Development and Innovation Funding through the project: "Empirical modelling and experimental development of emerging technologies tools for online social networks (FutureWeb)", code: PN-III-P1-1.2-PCCDI-2017-0800.

\section{References}

1. Boboc, R. G., Duguleana, M., Voinea, G. D., Postelnicu, C. C., Popovici D. M. \& Carrozzino M (2019), Mobile augmented reality for cultural heritage: Following the footsteps of Ovid among different locations in Europe, Sustainability, 11, 1167, 1-20.

2. Coxon M, Kelly N \& Page S (2016) Individual Differences in Virtual Reality: Are Spatial Presence and Spatial Ability Linked?. Virtual Reality 20(4): 203-212

3. Klimova, A., Bilyatdinova, A. \& Karsakov, A. (2018), Existing Teaching Practices in Augmented Reality, Procedia Computer Science, 136, 5-15.

4. Marilescu, V. (2018), The impact of new technologies in the field of tourism services, International Conference "Risk in Contemporary Economy", XIXth Edition, 2018, Galati, Romania, 267-275.

5. Montero, A. \& Belaza, B. (2017), Towards an augmented reality fourth generation social networks, arXiv e-prints arXiv:1705.04798, retrieved from

https:/ / wi.adsabs.harvard.edu/abs/2017arXiv170504798M/abstract

6. Pons, S. B., Ruiz, B. C., Duong, M., Chartrand, J., Fai, S. \& Lerma, J. L. (2019), Augmented Reality Markerless Multi-Image Outdoor Tracking System for the Historical Buildings on Parliament Hill, Sustainability, 11, 4268, 1-15.

7. Phupattanasilp, P. \& Tong, S. R. (2019), Augmented reality in the integrative internet of things (ARIoT): Application for precision farming, Sustainability, 11, 2658, 1-17.

8. Rauschnabel, P. A., Felix, R. \& Hinsch, C. (2019), Augmented reality marketing: How mobile AR-apps can improve brands through inspiration, Journal of Retailing and Consumer Services, 49, 43-53.

9. Scaravetti, D. \& Doroszensky, D. (2019), Augmented Reality experiment in higher education, for complex system appropriation in mechanical design, Procedia CIRP 84, 197-202.

10. Scholz, J. \& Smith, A. N. (2016), Augmented reality: Designing immersive experiences that maximize consumer engagement. Business Horizons, 59, 149-161.

11. Shu, J., Kosta, S., Zheng, R. \& Hui, P. (2018), Demo: Talk2Me - A Framework for D2D Augmented Reality Social Network, in 2018 IEEE International Conference on Pervasive Computing and Communications Workshops, PerCom Workshops, 580-582.

12. Sorko, S. R. \& Brunnbofer, M. (2019), Potentials of Augmented Reality in Training, Procedia Manufacturing, 31, 85-90. 
International Conference "Risk in Contemporary Economy" ISSN-L 2067-0532 ISSN online 2344-5386 $X^{\text {th }}$ Edition, 2019, Galati, Romania,

"Dunarea de Jos" University of Galati, Romania - Faculty of Economics and Business Administration

13. Ullah, F., Sepasgozar, S. M. E. \& Wang, C. (2018), A systematic review of smart real estate technology: Drivers of, and barriers to, the use of digital disruptive technologies and online platforms, Sustainability, 10, 3142, 1-44.

14. Wassom, B. D. (2015). Augmented Reality Law, Privacy, and Ethics, Elsevier.

15. Zhao, H., Zhao, Q.H. \& Ślusarçyk, B. (2019), Sustainability and digitalization of corporate management based on augmented/virtual reality tools usage: china and other world it companies' experience, Sustainability, 11, 4717, 1-17.

16. https://futureweb.unitbv.ro/index.php/ro/rezultatele-proiectului-3, accessed on 05 April 2019. 